\title{
Detection of Methicillin Resistant Strains of Staphylococcus aureus Using Phenotypic and Genotypic Methods in a Tertiary Care Hospital
}

\author{
N. Lakshmi Priya*, K.G. Venkatesh, G. Sumathi and S. Geethalakshmi \\ Institute of Microbiology, Madras Medical College and Rajiv Gandhi Government General \\ Hospital, Chennai-600003, Tamil Nadu, India \\ *Corresponding author
}

\section{A B S T R A C T}

Detection of Methicillin resistant strains of Staphylococcus aureus using phenotypic and genotypic methods in a tertiary care hospital Institution: Institute of Microbiology, Madras Medical College. Abstract: Purpose: Methicillin resistant S. aureus (MRSA) are significant

Keywords

Skin and soft tissue infection, MRSA,

Phenotypic methods, mec A gene, Anti microbial susceptibility pattern.

Article Info

Accepted:

29 June 2017

Available Online:

10 July 2017 pathogens that have emerged over the past 30 years to cause both nosocomial and community acquired infections. This study has been undertaken to compare the conventional and molecular methods in detecting MRSA. S. aureus was isolated from pus samples and identified by Gram stain and Catalase test. Further confirmation was done by slide and tube coagulase test, growth on MSA, DNA se test. Methicillin resistance was determined by disc diffusion method, oxacillin screen agar, micro broth dilution test and also by detection of mecA gene by multiplex PCR method. The antimicrobial susceptibility pattern of the isolates was determined by Kirby-Bauer disc diffusion method. Vancomycin resistance was determined by disc diffusion and E-test method as per CLSI guidelines. Results: A total of $150 \mathrm{~S}$. aureus was isolated from pus samples. Phenotypic methods detected $54 \%$ of isolates as methicillin resistant and $46 \%$ as methicillin susceptible. Detection of mecA gene was done by multiplex PCR in 50 isolates which showed 29 isolates $(58 \%)$ as methicillin resistant. All the isolates were sensitive to Vancomycin by disc diffusion method and E test. Antibiotic sensitivity results showed that MRSA strains were more resistant to antibiotics compared to methicillin sensitive Staphylococcus aureus (MSSA) isolates. Conclusion: The conventional phenotypic methods were comparable with that of mecA gene detection, the gold standard and hence it can be used in the detection of MRSA isolates.

\section{Introduction}

Skin and soft tissue infection are common type of infection that may contribute to longer hospital stays, significantly increase the cost of medical care and are likely to have an important role in the development of antimicrobial resistance ${ }^{1}$. Most of these infections are superficial and readily treated with a regimen of local care and antibiotics. However soft tissue infections involving deeper layers like fascia and muscle can rapidly progress to systemic sepsis and prove fatal $^{2}$. Staphylococcus aureus is one of the common organisms associated with soft tissue infection $^{3}$. Infections caused by $S$. aureus used to respond to beta-lactam group of antibiotics. Penicillin resistant $S$. aureus strains began emerging in 1940. Resistance to methicillin was noticed as early as in $1961^{4}$. 
The prolonged hospital stay, indiscriminate use of antibiotics and the lack of awareness are possible predisposing factors for MRSA emergences ${ }^{5}$. Many of the MRSA strains are multi-drug resistant and are susceptible only to glycopeptide antibiotics such as vancomycin ${ }^{6}$. Hence this study has been undertaken to compare the conventional and molecular methods in detecting MRSA and also in detecting the antimicrobial susceptibility pattern of the isolates.

\section{Materials and Methods}

\section{Selection of sample}

The study was carried out at Institute of Microbiology, Madras Medical College. Pus samples were collected from skin and soft tissue infections from patients admitted in General Surgery and allied specialties at Government General Hospital, Chennai. Ethical and research clearance was obtained from the Institute of Ethical Committee Government General Hospital and Madras Medical College.

\section{Sample processing}

The collected pus samples were subjected to direct Gram stain and inoculated onto nutrient agar, blood agar and Mac Conkey agar. The plates were incubated at $37^{\circ} \mathrm{C}$ and inspected after overnight incubation. Staphylococcus aureus was identified by its colony morphology, Gram stain and catalase test. Further confirmation was done by slide and tube coagulase test, growth on Mannitol salt agar and DNase test by standard microbiological techniques as recommended by CLSI guidelines ${ }^{7}$.

\section{Detection of methicillin resistance}

\section{Disc diffusion method}

Methicillin resistance was determined by

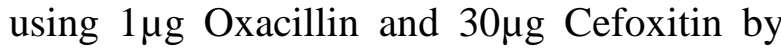

Kirby Bauer disc diffusion method and incubating at $35^{\circ} \mathrm{C}$ for 24 hours $^{7}$.

\section{Oxacillin screen agar}

Oxacillin working solutions $6 \mu \mathrm{g} / \mathrm{ml}$ is prepared and added to Mueller Hinton agar with $4 \% \mathrm{NaCl}$. Staphylococcus aureus culture corresponding to 0.5 McFarland turbidity standard is prepared and spot inoculated on the agar. The plates were incubated for 24 hours at $35^{\circ} \mathrm{C}$. The appearance of even a single colony on Oxacillin screen agar indicates Oxacillin resistance ${ }^{8}$.

\section{Determination of MIC - Oxacillin by broth microdilution method}

Inoculums were prepared by inoculating single purified colonies of bacterial and control strains into Mueller Hinton Broth and incubated overnight at $37^{\circ} \mathrm{C}$. Optical density was measured with a spectrophotometer at $546 \mathrm{~nm}$. The density of the inoculum was adjusted to $10^{5} \mathrm{CFU} / \mathrm{ml}$ and used in MIC determination. MIC was determined in duplicate in Mueller Hinton Broth containing serial two-fold dilutions of Oxacillin with inoculated bacterial suspensions of $10^{5}$ $\mathrm{CFU} / \mathrm{ml}$ as outlined by CLSI. The results were recorded after overnight incubation at $37^{\circ} \mathrm{C}$. The MIC was defined as the lowest antibiotic concentration with no visible growth ${ }^{9}$.

\section{Determination of mecA gene by Multiplex PCR method}

The mec A gene codes for Penicillin Binding Protein 2A (PBP2A) that is responsible for methicillin resistance. The mecA gene is highly conserved among Staphylococcal species, therefore presently detection of this gene by PCR is considered as 'gold standard' for detection of methicillin resistance in Staphylococci ${ }^{10}$. 
Molecular diagnostic assays based on the detection of the mecA gene encountered difficulty in discriminating MRSA from methicillin resistant coagulase negative Staphylococcus species (MR-CoNS) because the mecA gene is widely distributed in $S$. aureus as well as in MR-CoNS ${ }^{11}$.

In this study multiplex PCR was used which allows the detection of MRSA by using primers specific for methicillin resistance and coagulase genes. The coag gene was used to differentiate between $S$. aureus and CoNS, a gene which allows species specific identification of $S$. aureus. In addition MRSA harbours the mecA gene encoding methicillin resistance, which is absent in methicillin susceptible Staphylococci ${ }^{11}$.

Cell lysates of the isolates were used as DNA template for colony lysates PCR. Two sets of primers were used for multiplex PCR. The first pair of primers was derived from the region of the mecA gene.

The second pair of primers was derived from the region of the coag gene. Forty amplification cycles were performed with an automated thermocycler.

Amplified products were run using horizontal $1.5 \%$ agarose gel electrophoresis. The gel was visualized using a UV transilluminator.

The amplified PCR products and 100 base pair DNA molecular markers were seen as bright florescent bands ${ }^{6}$. A 533bp corresponds to $m e c A$ and $810 \mathrm{bp}$ corresponds to coag gene specific oligo nucleotides.

\section{Detection of antimicrobial susceptibility pattern}

The sensitivity to common antibiotics was done by Kirby-Bauer disc diffusion method as recommended by $\mathrm{CLSI}^{7}$.

\section{Determination of vancomycin resistance by disc diffusion}

Testing for vancomycin resistance was done by using $30 \mu \mathrm{g}$ vancomycin disc by Kirby Bauer disc diffusion method ${ }^{7}$.

\section{MIC for vancomycin by E-test}

Epsilometer (E-test) is based on a combination of both diffusion and dilution tests. It consists of a strip made of inert material with 8 extensions that carry the discs of $4 \mathrm{~mm}$, resembling the 'tooth of comb'.

A defined concentration of antibiotic is loaded on each of the disc so as to form a gradient when placed on agar plate. A 0.5 McFarland turbidity standard of $S$. aureus was inoculated as a lawn culture on Mueller Hinton Agar with 2\% NaCl.

E-strips were placed on the agar surface and plates were incubated at $35^{\circ} \mathrm{C}$ for 24 hours. MIC was read where the ellipse intersects the scale $^{11}$.

\section{Statistical analysis used}

Statistical package for social sciences (SPSS) and Epi- info

\section{Results and Discussion}

Methicillin resistance was determined for a total of $150 \mathrm{~S}$. aureus isolates from pus samples by oxacillin and cefoxitin disc diffusion method, oxacillin screen agar, MICbroth microdilution method and PCR for $m e c A$ gene. Most of the isolates were from orthopedics department 51 (34\%) followed by general surgery 42 (28\%) (Table 1).

$53.3 \%$ of the strains were found to be resistant, $3.3 \%$ were intermediate and $43.3 \%$ were susceptible strains by oxacillin disc 
diffusion method (Table 2) $46 \%$ of strains were sensitive and $54 \%$ were resistant by cefoxitin disc method and microbroth dilution method and oxacillin screen agar method (Table 3).

Among MRSA strains, high level oxacillin resistance $\geq 32 \mu \mathrm{g} / \mathrm{ml}$ was found in 58 strains. Moderate level resistance $\leq 16 \geq 8 \mu \mathrm{g} / \mathrm{ml}$ was found in 19 strains (13\%). Low level resistance $4 \mu \mathrm{g} / \mathrm{ml}$ was found in 5 strains $(3 \%)$ (Table 4).

Multiplex PCR for the detection of mecA gene and coag gene detected 29 strains (58\%) as methicillin resistant and 21 strains $(42 \%)$ as methicillin susceptible (Table 5). Among MRSA strains all strains $(100 \%)$ were resistant to penicillin. More than $80 \%$ strains were resistant to cefotaxime, cephalexin, cefaclor, ampicillin, gentamicin and erythromycin. Moderate level of resistance was detected to ciprofloxacin, co-trimoxazole, amikacin and ofloxacin. However the strains were highly sensitive to chloramphenicol and rifampicin. $100 \%$ sensitivity was observed to vancomycin, teicoplanin and linezolid (Table 6). Among the MSSA strains, $95.6 \%$ strains were resistant to penicillin, moderate level of resistance were seen to ampicillin, cotrimoxazole and cephalexin. However majority of strains were sensitive to cefotaxime, erythromycin, chloramphenicol, ciprofloxacin, ofloxacin and rifampicin. All strains were sensitive to vancomycin, teicoplanin and linezolid (Table 7). All strains were sensitive to vancomycin by E-test method also (Table 8).

Table.1 Distribution of the sample source

\begin{tabular}{|l|l|l|}
\hline \multicolumn{2}{|l}{$\mathrm{N}=150$} \\
\hline Speciality & No. of cases & Percentage \\
\hline 1. Orthopedics & 51 & 34 \\
\hline 2. General Surgery & 42 & 28 \\
\hline 3. Neuro Surgery & 17 & 11.3 \\
\hline 4. Dermatology & 30 & 20 \\
\hline 5.Cardiothoracic Vascular Surgery & 4 & 2.7 \\
\hline 6. Otorhino layrngology & 4 & 2.7 \\
\hline 7. Gastroenterology & 2 & 1.4 \\
\hline
\end{tabular}

Table.2 Results of methicillin resistance in $S$. aureus as determined by oxacillin (1ug) disc diffusion method

\begin{tabular}{|l|l|l|}
\hline Pattern of Resistance & No. of cases & Percentage \\
\hline 1) Susceptible & 65 & 43.3 \\
\hline 2) Intermediate & 5 & 3.3 \\
\hline 3) Resistant & 80 & 53.3 \\
\hline
\end{tabular}

Table.3 Results of methicillin resistance in $S$. aureus as determined by cefoxitin $(30 \mu \mathrm{g})$ disc diffusion method, microbroth dilution method and oxacillin screen agar method

\begin{tabular}{|l|l|l|}
\hline Pattern of Resistance & No. of cases & Percentage \\
\hline 1) Susceptible & 69 & 46 \\
\hline 2) Resistant & 81 & 54 \\
\hline
\end{tabular}


Table.4 Pattern of Oxacillin Resistance among MRSA isolates

\begin{tabular}{|l|l|l|l|}
\hline $\begin{array}{l}\text { Oxacillin } \\
\text { Resistance Pattern }\end{array}$ & MIC $\boldsymbol{\mu G} / \mathbf{M L}$ & No. of cases & Percentage \\
\hline High-level & $\geq 32 \mu \mathrm{g} / \mathrm{ml}$ & 58 & 71 \\
\hline Moderate level & $\leq 16 \geq 8 \mu \mathrm{g} / \mathrm{ml}$ & 19 & 23 \\
\hline Low level & $4 \mu \mathrm{g} / \mathrm{ml}$ & 5 & 6 \\
\hline
\end{tabular}

Table.5 Results of MEC A gene detection by PCR

\begin{tabular}{|l|l|l|}
\hline mec $\boldsymbol{A}$ & Total no. of cases & Percentage $\quad \mathrm{N}=50$ \\
\hline Positive & 29 & 58 \\
\hline Negative & 21 & 42 \\
\hline
\end{tabular}

Table.6 Anti-microbial susceptibility pattern of MRSA

\begin{tabular}{|l|l|l|l|}
\hline Antibiotics & $\begin{array}{l}\text { Susceptible } \\
(\%)\end{array}$ & $\begin{array}{l}\text { Intermediate } \\
(\%)\end{array}$ & $\begin{array}{l}\text { Resistant } \\
(\%)\end{array}$ \\
\hline Penicillin & & & 100 \\
\hline Cefotaxime & & 4 & 96 \\
\hline Cephalexin & 6 & & 94 \\
\hline Ampicillin & 8 & & 92 \\
\hline Gentamicin & 16.4 & 3.6 & 80 \\
\hline Erythromycin & 10.5 & 9.5 & 80 \\
\hline Cefaclor & 22 & & 78 \\
\hline Ciprofloxacin & 11 & 12 & 77 \\
\hline Co- trimoxazole & 36 & & 64 \\
\hline Amikacin & 30.5 & 25.6 & 44 \\
\hline Ofloxacin & 49 & 11 & 40 \\
\hline Chloramphenicol & 78.1 & 7.3 & 14.6 \\
\hline Rifampicin & 85.4 & 7.3 & 7.3 \\
\hline Vancomycin & 100 & & \\
\hline Teicoplanin & 100 & & \\
\hline Linezolid & 100 & & \\
\hline
\end{tabular}


Table.7 Anti-microbial susceptibility pattern of MSSA

\begin{tabular}{|l|l|l|l|}
\hline Antibiotics & $\begin{array}{l}\text { Sensitive } \\
(\mathbf{\%})\end{array}$ & $\begin{array}{l}\text { Intermediate } \\
(\mathbf{\%})\end{array}$ & $\begin{array}{l}\text { Resistant } \\
(\mathbf{\%})\end{array}$ \\
\hline Penicillin & 4.4 & & 95.6 \\
\hline Ampicillin & 22 & & 78 \\
\hline Cephalexin & 38 & & 62 \\
\hline Cefotaxime & 75 & & 25 \\
\hline Cefaclor & 71 & & 29 \\
\hline Erythromycin & 52.4 & 17.6 & 31 \\
\hline Chloramphenicol & 92.6 & & 8.8 \\
\hline Co - trimoxazole & 46 & & 54 \\
\hline Gentamicin & 57.3 & 4.4 & 39.7 \\
\hline Amikacin & 60.2 & 22 & 17.6 \\
\hline Ciprofloxacin & 53 & 17.6 & 30.8 \\
\hline Ofloxacin & 59.7 & 13.2 & 28.5 \\
\hline Vancomycin & 100 & & \\
\hline Teicoplanin & 100 & & \\
\hline Linezolid & 100 & & 2 \\
\hline Rifampicin & 98 & &
\end{tabular}

Table. 8 Results of vancomycin resistance determined by disc diffusion and E test method

\begin{tabular}{|l|l|l|}
\hline Pattern of resistance & No. Of cases & Percentage $\mathrm{N}=150$ \\
\hline Susceptible & 150 & $100^{\prime}$ \\
\hline Intermediate & - & - \\
\hline Resistant & - & - \\
\hline
\end{tabular}

Oxacillin disc diffusion method was not reliable for the identification of methicillin intermediate strains. Cefoxitin is a better inducer of mec $A$ gene and disc diffusion tests using cefoxitin give clearer end points and are easier to read than tests with oxacillin. The present study reveals that using cefoxitin is a good alternative method for oxacillin disc diffusion method for the detection of MRSA especially in the identification of intermediate resistant strains of S. aureus.

The conventional MRSA detection assays are simple and relatively cheap in detecting methicillin resistance. Accurate determination of MRSA by conventional methods is subjected to variation in inoculum size, incubation time, temperature, $\mathrm{pH}$ and salt concentration. It is in such instance that detection of mec $A$ gene is useful by molecular methods ${ }^{12}$. In this study, multiplex PCR was used to detect the presence of mec A gene and coag gene in 50 isolates. In this study, on comparing the phenotypic and genotypic results of the 50 isolates, the phenotypic methods such as oxacillin screen agar, cefoxitin disc diffusion, MICmicrobroth dilution methods, had sensitivity of $90 \%$, specificity of $100 \%$ and accuracy of 94\%. The phenotypic results are therefore comparable with that of mec A- the gold standard. In the present study, the antibiotic sensitivity results show that all MRSA isolates were more resistant to antibiotics as 
compared to MSSA isolates. In this study disc diffusion method and E-test detected all isolates of $S$. aureus as vancomycin sensitive.

High methicillin resistance observed in this study warrants the need for screening for MRSA as a routine procedure in clinical laboratories.

\section{References}

1. Martone WJ. Nicholas RL 2001, Recognition, Surveillance and management of surgical site infections Clin. Infect Dis: 33, S67 - S106.

2. Song MD, Wachi. M. Doi M, Ishino. F, Malsusiashi M. 1987 Evaluation of an inducible penicillin - target protein in methicillin - resistant Staphylococcus aureus by gene fusion. Febs Lect: 221: $167-171$.

3. Sakoulas G Gold HS, Venkataraman et al., 2001 methicillin - resistant Staphylococcus aureus: comparison of susceptibility testing methods and analysis of mec $A$ - positive susceptible strains. J. Clin microbial: 39. $3946-51$.

4. Sharon J Peacock: 2003 Staphylococcus; Topley and Wilson's Microbiology and Microbial infection 10 ${ }^{\text {th }}$ Edition. 32: $771-831$.

5. Assadullah S. Karkeri Thahar MA Emergency of low level vancomycin resistance in MRSA. Indian $J$ Med Microbiol; 21; 196 - 8 .
6. Rallapalli S. (2008Validation of Multiplex PCR Strategy for simultaneous detection and identification of methicillin resistant Staphylococcus aureus. Indian Journal of Medical Microbiology) 26 (4): 361-4.

7. Clinical laboratory standard institute 2007 Performance standards for antimicrobial susceptibility testing. CLSI Approved standard M 100 - S17, CLSI - Wayne, PA.

8. Deeker. F.J. Brown 2005- Guidelines for the laboratory diagnosis and susceptibility testing of methicillin resistant Staphylococcus aureus (MRSA) - Journ. of Antimicrobial chemotherapy, 56: $1000-1018$.

9. National Committee for clinical laboratory standards. Method for dilution Antimicrobial susceptibility tests for Bacteria that Grow aerobically: approved standard 2003.M7 - A6 NCCLS. Wayne P.A. USA

10. Bragnardi GE, Chapman a et al., 1996 Detection of the mec $A$ gene and phenotypic detection of resistance in Staphylococcus aureus isolates with borderline or low - level methicillin resistance. J. Antimicrob chemother; 37, $53-63$.

11. Rahbar et al., 2006. Evaluation of cefoxitin disk for detection of methicillin resistant Staphylococcus aureus - ESCMID - 1-4-2006.

\section{How to cite this article:}

Lakshmi Priya, N., K.G. Venkatesh, G. Sumathi and Geethalakshmi, S. 2017. Detection of Methicillin Resistant Strains of Staphylococcus aureus Using Phenotypic and Genotypic Methods in a Tertiary Care Hospital. Int.J.Curr.Microbiol.App.Sci. 6(7): 4008-4014. doi: https://doi.org/10.20546/ijcmas.2017.607.415 